\title{
Hazards of closed pesticide mixing and loading systems: the paradox of protective technology in the Third World
}

\author{
Rob McConnell, Mario Cordón, Douglas L Murray, Ralph Magnotti
}

\begin{abstract}
In studies in developing countries, closed systems for mechanically mixing and loading hazardous pesticides have been shown to reduce exposure to workers. To evaluate the efficacy of closed systems in preventing worker exposure in the developing world, a cross sectional study was conducted at rural crop dusting airports in the cotton growing region of Nicaragua. Worker exposure was evaluated by measuring the activity of erythrocyte cholinesterase in the field with a new design battery operated colorimeter. The 10 mixer loaders at four airstrips with closed systems were compared with the 16 mixer loaders at four airstrips where pesticides were hand poured. Paradoxically, cholinesterase activity was $1 \cdot 1$ IU $/ \mathrm{ml}$ blood (95\% Cl 0.49-1.8) lower (inhibited) among workers in airstrips with closed systems than among workers hand pouring insecticides, after adjusting for weight of organophosphates sprayed in the past 14 days, and for prior training in safe use of pesticides. Mixer loaders with prior training had cholinesterase activity $0.83 \mathrm{IU}(95 \% \mathrm{Cl} 0.30-1.4)$ higher than untrained workers, and the weight of organophosphates sprayed was also a statistically significant predictor in the model. Unfortunately, management viewed the closed systems primarily as a production tod, rather than as a way to protect workers. Airstrips with closed
\end{abstract}

Division of Occupational and Environmental Medicine, Mount Sinai Medical Centre, New York, New York and American Friends Service Committee, Philadelphia, Pennsylvania, USA

R McConnell

CARE Nicaragua, Managua, Nicaragua

M Cordon

Centre for Latin American Studies, Stanford University, Stanford, California, USA

L Murray

Division of Nephrology, University of Cincinnati School of Medicine, Cincinnati, Ohio, USA

R Magnotti systems were able to apply an average of $3250 \mathrm{lb}$ organophosphates per worker in the 14 days before the survey compared with $849 \mathrm{lb}$ per worker in airstrips without closed systems. Only three of 10 mixer-loaders at airstrips with closed systems had received formal training in safer use of pesticides. Because of shortage of personnel and transport, it was difficult for the responsible government agencies to train workers adequately and to enforce pesticide health and safety standards at multiple dispersed worksites.

Mixing and loading pesticide concentrates into crop dusters is one of the jobs most highly exposed to pesticides. To protect mixer-loaders, California has passed pioneering regulations requiring the use of closed system mixing and loading equipment at crop dusting airstrips where workers are exposed to US Environmental Protection Agency category I (most hazardous) pesticides.' These systems, consisting of a pump and tubing, which automatically mix and load crop dusters without workers having contact with pesticides, are reported to decrease worker exposure by as much as 10 fold. $^{2}$

Pesticide poisoning has long been a major public health problem on Nicaragua's northern Pacific coastal plain, comprising the departments of Leon and Chinandega, the country's principal cotton growing region..$^{3-6}$ The large cotton fields are traditionally sprayed with acutely toxic organophosphate insecticides by crop dusting aeroplanes as many as 28 times in one season. ${ }^{7}$ In 1984 there were 27 poisonings reported in one year among a total of only 200-300 mixer-loaders in the region. ${ }^{6}$ As a result, starting in 1985 closed system mixing and loading units were installed in a pilot programme to prevent poisonings and to shift mixing and loading from the airports in the cities to smaller landing strips away from the major population centres. Closed systems were offered at nominal cost to all 50 licenced airstrips in the region, but had been purchased by only 21 at the time of this study. 
To evaluate the efficacy of the closed systems in preventing exposure of mixer-loaders to pesticides in a Third World setting, a cross sectional study was conducted comparing symptoms and exposure to pesticides among workers at airstrips with and without closed mixing and loading systems.

\section{Methods}

In November and December 1987 four airstrips where closed systems had been installed within the two previous years were compared with four where no closed systems existed. Mixer-loaders diluted concentrated pesticides with water for application. Hand pouring of concentrated pesticides, either directly into the crop duster or into a mix tank, resulted in spills and contamination of the worker. The closed mixing and loading systems used a graduated probe inserted into the pesticide container to measure the volume of concentrate to be pumped to a mix tank where concentrate was diluted with water. Diluted pesticide was then pumped to the crop duster, all without direct worker exposure. These systems complied with California Department of Food and Agriculture regulations. ${ }^{2}$

From among the 21 airstrips in the region with closed systems, four were selected for study because they were close to the regional capital (Leon). Three small private airstrips with closed systems were matched to three small private airstrips without closed systems in the same geographic area. One large state farm was matched with a nearby large private airstrip.

At each airstrip an inspection was made to see if personal protective equipment (rubber boots, overalls, and gloves) was in good condition (clean and without holes or tears), and if soap was available to workers. Records were reviewed to calculate the weight and composition of organophosphate concentrate applied in the 14 days before the visit. All 33 mixer-loaders (all men) present at the airstrips participated in the study. Each worker was administered a questionnaire about symptoms experienced during the previous week compatible with exposure to cholinesterase inhibitors (headache, dizziness, blurred vision, frequent spitting (sialorrhea), stomach ache, anorexia, nausea or vomiting). Also, each worker was asked about history of pesticide poisoning, and about training he had received on the safe use of pesticides. As a surrogate for direct measurement of exposure to pesticides, the activity of erythrocyte cholinesterase was measured quantitatively on a single occasion using a battery operated field kit of new design (EQM Inc, Cincinnati, Ohio), which performs the Ellman assay on a finger stick sample of blood. ${ }^{5}$ (Cholinesterase activity is inhibited by the organophosphate insecticides used in cotton spraying.)
Forty two healthy, male health workers in administrative, clerical, or maintenance jobs in the regional health authority in Leon, Nicaragua were sampled to establish a lower normal limit of cholinesterase activity of 3.7 international units (IU) $/ \mathrm{ml}$ blood (mean 4.5; standard deviation (SD) $0.54 ; 90 \%$ confidence interval $(90 \% \mathrm{CI}) 3 \cdot 7-5 \cdot 6$; range $3 \cdot 7-5 \cdot 7)$. All these workers reported that they had no history of exposure to pesticide during the three months before the examination.

Confidence intervals for relative risk of low cholinesterase activity for various risk factors were calculated using the test based method of Miettinen. ${ }^{8}$ Differences between mean cholinesterase activities were calculated using a $t$ statistic for a pooled variance estimate. ${ }^{9}$ Multiple linear regression was done using SPSS-PC. ${ }^{10}$

\section{Results}

Organophosphate pesticides sprayed from one or more of the airstrips during the two weeks before the study included acephate, chlorpyrifos, ethyl parathion, malathion, mephosfolan, methamidophos, and methyl parathion. Seventy one per cent (by weight) of organophosphates applied at the eight airstrips were applied at the four airstrips with closed mixing and loading systems (32 $504 \mathrm{lb}$ compared with only $13586 \mathrm{lb}$ at the airstrips without closed systems). There was an average of 2.5 mixer-loaders at airstrips with closed systems (range 2-3) compared with an average of 4.0 at airstrips without closed systems (range 3-5). The difference between the weight of organophosphates applied per mixer-loader in the two types of airstrips was even more pronounced than that between airstrips $(3250 \mathrm{lb}$ per worker at the closed system airstrips compared with $849 \mathrm{lb}$ at the airstrips without closed systems). The airstrips without closed systems generally used more potent (US Environmental Protection Agency category I) cholinesterase inhibiting organophosphates (12 893 $(95 \%)$ of $13586 \mathrm{lb}$ total organophosphates) than did airstrips with closed systems (26 $277(79 \%)$ of $32504 \mathrm{lb}$ total).

Of the 33 study participants, seven were supervisors who had less direct contact with pesticides than did other mixer-loaders. The mean erythrocyte cholinesterase activity was $4.3 \mathrm{IU} / \mathrm{ml}$ blood (SD 0.29 ; range 3.9-4.7) among the seven supervisors, compared with 3.7 IU (SD 0.74 ; range $2.4-5.0$ ) among all 26 other mixer-loaders (difference $=0.6$ IU; $95 \% \mathrm{CI}=0,1 \cdot 3)$. All supervisors had activity in the normal population range (compared with 16 $(62 \%)$ of the other 26 mixer-loaders). Because they were less exposed, supervisors were excluded from subsequent analyses.

Table 1 compares the 26 non-supervisory mixerloaders at the two types of airstrips with regard to demographic characteristics and potential risk fac- 
Table 1 Characteristics of mixer-loaders at airstrips with and without closed systems

\begin{tabular}{|c|c|c|c|c|}
\hline Characteristic & \multicolumn{2}{|c|}{$\begin{array}{l}\text { With closed } \\
\text { systems } \\
(n=10)\end{array}$} & \multicolumn{2}{|c|}{$\begin{array}{l}\text { Without closed } \\
\text { systems } \\
(n=16)\end{array}$} \\
\hline Mean age (y (SD)) & $30 \cdot 8$ & $(7 \cdot 1)$ & 28 & $(6 \cdot 8)$ \\
\hline $\begin{array}{l}\text { Low cholinesterase activity } \\
(<3.7 \mathrm{IU} / \mathrm{ml} \text { blood })\end{array}$ & 5 & $(50 \%)$ & 5 & $(31 \%)$ \\
\hline Received formal training in safe & & & & \\
\hline $\begin{array}{l}\text { use of pesticides } \\
\text { Gloves, overalls, and boots }\end{array}$ & 3 & $(30 \%)$ & 3 & $(18 \%)$ \\
\hline available and in good condition & 5 & $(50 \%)$ & 8 & $(50 \%)$ \\
\hline Soap available at work site & 4 & $(40 \%)$ & 16 & $(100 \%)$ \\
\hline
\end{tabular}

tors for increased exposure to pesticide. Only three workers in each group reported having received formal training on the safe use of pesticides and only $40 \%$ of mixer-loaders at airstrips with closed systems had soap at the work site (compared with $100 \%$ among the workers without closed systems).

Table 2 presents the relation between cholinesterase activity and risk factors for low cholinesterase activity. Paradoxically, the mean cholinesterase activity of workers at airstrips with closed systems (mean $3.3 \mathrm{IU} / \mathrm{ml}$ blood; SD $0 \cdot 60$; range $2 \cdot 4-4 \cdot 1$ ) was lower (worse) than among workers at airstrips without closed systems (mean $3.9 \mathrm{IU} / \mathrm{ml}$ blood; SD 0.75; range $2 \cdot 6-5 \cdot 0)$. The mean cholinesterase activity among workers with closed systems was less than the lower normal population limit of $3.7 \mathrm{IU} / \mathrm{ml}$ blood. Previous training in the safe use of pesticides appeared to have a protective effect against depression of cholinesterase activity. Although there was a lower proportion of workers with low cholinesterase activity and slightly higher mean cholinesterase activity among workers with personal protective equipment and access to soap, the differences were not statistically significant. No relation was found between symptoms compatible with organophosphate exposure and cholinesterase activity.

In a multiple linear regression procedure, cholinesterase activity was modelled as a function of work with closed systems, controlling for history of training in the safe use of pesticides and weight of organophosphates applied per mixer-loader at each airstrip. The model was a good predictor of erythrocyte cholinesterase activity (adjusted $\mathrm{r}^{2}=0.39$; $F=6.40 ; p=0.003)$. The presence of a closed system was still associated with $1 \cdot 1 \mathrm{IU} / \mathrm{ml}$ blood lower cholinesterase activity (95\% CI $0.49-1 \cdot 8)$, even after controlling for potential confounders. Those workers who had received previous training in the safe use of pesticides had mean cholinesterase activity $0.8 \mathrm{IU} / \mathrm{ml}$ blood higher than those who had not (95\% CI 0-3-1.4). Weight of organophosphates (lb) applied per worker at the airport (as a continuous variable) was also significantly associated with lower cholinesterase activity $\left(95 \%\right.$ CI $2.0 \times 10^{-4}-3.8$ $\left.\times 10^{-4}\right)$. The availability of personal protective equipment (gloves, overalls, and rubber boots) and of soap were not significantly associated with lower

Table 2 Mean cholinesterase activity and frequency of low cholinesterase activity $(<3 \cdot 7 \mathrm{IU} /$ ml blood) among mixer-loaders by selected characteristics

\begin{tabular}{|c|c|c|c|c|}
\hline Risk factor & $\begin{array}{l}\text { No with low } \\
\text { cholinesterase (\%) } \\
\text { activity }\end{array}$ & $\begin{array}{l}\text { Relative risk } \\
(95 \% \text { CI })\end{array}$ & $\begin{array}{l}\text { Mean } \\
\text { cholinesterase } \\
\text { activity }(I U / m l)\end{array}$ & $\begin{array}{l}\text { Difference of means } \\
(95 \% C I)\end{array}$ \\
\hline $\begin{array}{l}\text { Workers at airstrips without closed } \\
\text { systems }(n=16)\end{array}$ & $5(31)$ & $0.62(0.31$ to $1 \cdot 2)$ & 3.9 & $0.6(0.04$ to 1.2$)$ \\
\hline $\begin{array}{l}\text { Workers at airstrips with closed } \\
\text { systems }(n=10)\end{array}$ & $5 \quad(50)$ & & $3 \cdot 3$ & \\
\hline $\begin{array}{l}\text { Have not received training in } \\
\text { poisoning prevention }(n=20)\end{array}$ & $9 \quad(45)$ & $2.6 \quad(0.22$ to 31$)$ & $3 \cdot 5$ & $-0.7(-0.1$ to $-0.1 \cdot 4)$ \\
\hline $\begin{array}{l}\text { Training in poisoning prevention } \\
(\mathbf{n}=6)\end{array}$ & $1 \quad(17)$ & & $4 \cdot 2$ & \\
\hline $\begin{array}{l}\text { Airstrips spraying } 1000 \text { or more } \\
\text { lb/worker }(n=10)\end{array}$ & $4 \quad(40)$ & $1.1 \quad(0.48$ to $2 \cdot 3)$ & $3 \cdot 6$ & $-0.1(-0.8$ to 0.5$)$ \\
\hline $\begin{array}{l}\text { Airstrips spraying less than } 1000 \\
\text { lb/worker }(n=16)\end{array}$ & $6 \quad(38)$ & & $3 \cdot 7$ & \\
\hline $\begin{array}{l}\text { Incomplete personal protective } \\
\text { equipment available }(n=13)\end{array}$ & $6(46)$ & $1.5 \quad(0.22$ to 10$)$ & $3 \cdot 6$ & $-0.2(-0.4$ to 0.8$)$ \\
\hline $\begin{array}{l}\text { Complete personal protective } \\
\text { equipment available }(n=13)\end{array}$ & $4(31)$ & & $3 \cdot 8$ & \\
\hline $\begin{array}{l}\text { Soap not available }(n=6) \\
\text { Soap available }(n=20)\end{array}$ & $\begin{array}{ll}3 & (50) \\
7 & (35)\end{array}$ & $1.4 \quad(0.03$ to 64$)$ & $\begin{array}{l}3 \cdot 3 \\
3 \cdot 8\end{array}$ & $-0.5(-1.2$ to 0.3$)$ \\
\hline $\begin{array}{l}\text { More than two symptoms compatible } \\
\text { with cholinesterase inhibitors } \\
(n=5)\end{array}$ & $2(40)$ & $1.1 \quad(0.11$ to 12$)$ & $3 \cdot 7$ & $0 \quad(-0.8$ to 0.8$)$ \\
\hline $\begin{array}{l}\text { Two or fewer symptoms compatible } \\
\text { with cholinesterase inhibitors } \\
(n=21)\end{array}$ & $8 \quad(38)$ & & $3 \cdot 7$ & \\
\hline
\end{tabular}




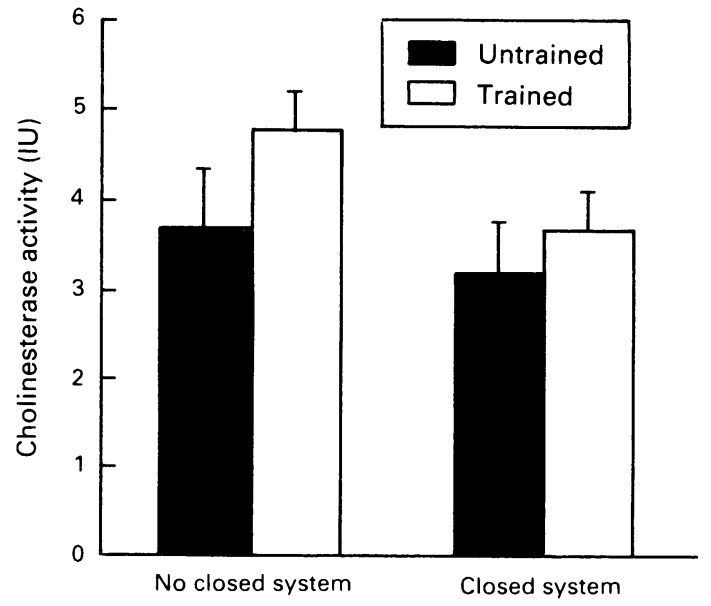

Mean cholinesterase activity ( $S D$ ) for trained and untrained workers at airstrips with and without closed systems.

cholinesterase activity $(p>0.05)$ and were not included in the final model. The figure shows the paradoxically lower mean cholinesterase activity among mixer-loaders at airstrips with closed systems, and the beneficial effect of training at both types of airstrips.

\section{Discussion}

Unfortunately, records were not available to determine whether the amounts of pesticides applied two years previously (before the installation of closed systems) were similar in the two groups of airstrips. Although it is not clear that the two groups were strictly comparable in this important respect before the installation of closed systems, it was reported by workers that the weight of pesticides sprayed had increased in those airstrips where closed systems were installed. After controlling for the weight of organophosphates applied and other potential confounders, the presence of closed systems was associated with lower cholinesterase activity.

The transfer of hazardous industrial technology to the Third World has been criticised, because often the protective technology used in the developed world is not also transferred. ${ }^{11}$ We believe this study shows the paradox of increased hazard associated with the transfer of a protective technology that is inappropriately applied to the Third World. Unlike developed countries, where use of a pump (with or without closed system technology) is routine in crop dusting airstrips, the owners of the Nicaraguan airstrips viewed the closed systems as a production tool (not as a health promotion tool). The owners of the airstrips were eager to buy the closed systems because the subsidy provided for the system made it cheaper than buying a pump alone on the open market. The use of a pump made it possible to fill the crop dusters much faster than with the traditional hand pouring method. The owner could spray his own crops faster, employing fewer mixer-loaders, and he could rent the use of the airstrip to his neighbours. This may have accounted in part for the greater use of pesticides by the closed system airstrips. Also, although the proper use of the closed system was faster than hand pouring concentrate and water diluent, the fastest way to load a crop duster was to load the water diluent by pump and to hand pour the concentrate. In cases where this occurred, it is likely to have resulted in considerably greater exposure than if the whole loading process (water and concentrate) were done by the slower hand pouring method.

In reviewing the California publications on the prevention of exposure by closed systems, it is clear that proper training is considered essential to the success of the equipment, ${ }^{12-14}$ and an important result of this study was the finding of the beneficial effect of training in reducing exposure. In a survey of these eight airstrips before the spraying season (four months before this study) only one of the 26 (nonsupervisory) mixer-loaders in the study was identified as being assigned to that task. The haphazard assignment of untrained personnel to this job and the high turnover of workers made improper use of the equipment likely. It also made it difficult to guarantee proper training for the workers.

A comprehensive plan to distribute personal protective equipment to workers, to conduct training seminars in safe use of pesticides, and to guarantee maintenance of the closed systems enjoyed support from three government ministries, the Agricultural Workers Union, and a consortium of non-government agencies. Unfortunately, as well as the problem of high turnover of mixers and loaders, it was difficult to get workers organised to come to a central location for training, and the lack of qualified personnel and transport made it extremely difficult for the Ministry of Health and the Ministry of Labour to reach the 50 rural airstrips in the region to train workers in proper use of closed systems and to obtain baseline cholinesterase activity before the start of spraying. It was difficult for the Ministry of Labour to enforce worker removal or job transfer provisions for workers with low cholinesterase activity or to sanction management for improper use of the closed systems.

By contrast with studies in developed countries, the availability of overalls, gloves, and boots had no influence on cholinesterase activity. Although dermal absorption is the most important route of exposure, ${ }^{1516}$ in practice workers rarely used gloves (perhaps the most important protection) and rarely wore respirators because the temperature often exceeded $32^{\circ} \mathrm{C}$ in the shade. The absence of any association between symptoms and depression of cholinesterase activity has also been reported in other 
studies, where symptoms have sometimes been found associated with chronic depression of cholinesterase activity and sometimes not. ${ }^{61718}$ Possible reasons include the absence of an unexposed comparison group, the limited power inherent to the small sample size, and the inability to evaluate the rate of decline of cholinesterase activity (an important determinant of symptoms).

In conclusion, the paradox presented by the failure of closed system pesticide mixing and loading to prevent exposure to organophosphates may be relevant to other Third World countries, and aid agencies considering the installation of closed systems for the prevention of pesticide poisoning should consider carefully the initial Nicaraguan experience. There are few data from other developing countries, but those that exist document overexposure of workers engaged in mixing and loading crop dusters for cotton spraying. ${ }^{19}{ }^{20}$ Although we continue to believe that closed system pesticide mixing and loading equipment can help prevent pesticide poisoning and pesticide overexposure, it is difficult to properly service multiple dispersed sites. We believe that spraying activities should be concentrated into a few large airstrips where closed systems can be installed and adequate supervision can be given to their use (as well as to work practices to prevent environmental contaminaion). Prospective studies should be conducted to evaluate the effect of closed systems on the weight of pesticides applied and to evaluate the change in cholinesterase activity (or other indices of exposure) associated with the introduction of closed systems. Finally, the problem of pesticide poisoning will not be solved until non-chemical alternatives for pest control can be implemented successfully.

We are grateful to Carmen Ibania Kuan, Donald Roque, and Mario Pais Nino for their collaboration in the collection of data, to Fresia Morales Cabrera for assistance in analysis of the results, and to Patrick Eberly and Kathryn Dowling for help in development of the field cholinesterase assay.

This study was supported by CARE Nicaragua, the American Friends Service Committee, the Nicaraguan Ministry of Health (region II), the Nicaraguan Ministry of Agricultural Development and Agrarian Reform, and the Agency for Toxic Substances and Disease Registry Clinical Fellowship in Environmental Medicine.

Requests for reprints to: Dr McConnell, Division of
Occupational and Environmental Medicine, Box 1057, Mount Sinai School of Medicine, New York, New York 10029, USA. Telephone 212-241-6173.

1 Title 3, California Administrative Code, chapter 6. Pesticides and control operations, group 3, pesticide worker safety. Sacremento, CA: Register 10-8-88;88 (No 41):402.14-402.15.

2 Rutz R, Gibbons D. Closed systems. Sacremento, CA: California Department of Food and Agriculture. Division of Pest Management, Environmental Protection and Worker Safety. Pesticide safety information series A-3 (HS-713). 7 November 1988.

3 McConnell R, Pacheco AF, Magnotti RA. Crop duster aviation mechanics: High risk for pesticide poisoning. American Journal of Public Health 1990;80:1236-9.

4 McConnell R. Epidemiology and occupational health in developing countries: Pesticides in Nicaragua. In: Hogstedt C, Reuterwall C, eds. Progress in Occupational Epidemiology. Amsterdam: Excerpta Medica, 1988:361-7.

5 Magnotti RA, Dowling K, Eberly PE, McConnell R. Field measurement of plasma and erythrocyte cholinesterases. Clin Chim Acta 1988;176:315-32.

6 Cole DC, McConnell R, Murray DL, Pacheco Anton F. Pesticide illness surveillance: The Nicaraguan experience. Bulletin of the Pan American Health Organisation 1988;22: 119-32.

7 Swezey SL, Murray DL, Daxl RG. Nicaragua's revolution in pesticide policy. Environment 1986;28:6-9, 29-36.

8 Schlesslman JJ. Case control studies. New York: Oxford University Press, 1982:206-7.

9 Daniel WW. Biostatistics: a foundation for analysis in the health sciences. New York: John Wiley and Sons, 1983:139.

10 Norusis MJ. The SPSS guide to data analysis for SPSS/PC+ Chicago: SPSS Inc, 1988.

11 Castleman BI. The export of hazardous factories to developing nations. International Journal of Health Services 1979;9: 569-606.

12 Rutz R. Closed system acceptance and use in California. In: Beestman GB, Vander Hooven DIB, eds. Pesticide formulations and application systems. Vol 7, ASTM STP 968. Philadelphia: American Society for Testing and Materials, 1987:28-34.

13 Knaak JB, Jackson T, Fredrickson AS, Rivera L, Maddy KT, Akesson NB. Safety effectiveness of pesticide mixing-loading and application equipment used in California in 1976. Arch Environ Contam Toxicol 1980;9:217-29.

14 Knaak JB, Jackson T, Fredrickson AS, Rivera L, Maddy KT, Akesson NB. Safety effectiveness of closed-transfer, mixingloading, and application equipment in preventing exposure to pesticides. Arch Environ Contam Toxicol 1980;9:231-45.

15 Durham WF, Wolfe HR. Measurement of the exposure of workers to pesticides. Bull World Health Organ 1962;26: 75-91.

16 Wolfe HR, Durham WF, Armstrong JF. Exposure of workers to pesticides. Arch Environ Health 1967;14:622-33.

17 Quinones MA, Bogden JD, Louria DB, El Nakah A, Hansen C. Depressed cholinesterase activities among farm workers in New Jersey. Sci Tot Environ 1976;6:155-9.

18 Duncan RC, Griffith J, Konefal J. Comparison of plasma cholinesterase among workers occupationally exposed to organophosphorus pesticides as reported by various studies. $J$ Toxicol Environ Health 1986;18:1-11.

19 Ullman L, Phillips J, Sachsse K. Cholinesterase surveillance of aerial applicators and allied workers in the democratic republic of the Sudan. Arch Environ Contam Toxicol 1979;8:703-12.

20 El-Refai AR, El-Essawi M, El-Esnawi N, Risk F. Hazards from aerial spraying in cotton culture area of the Nile River. Arch Environ Health 1971;22:328-33.

Accepted 6 January 1992 